\title{
Formulation and development of floating multiple-unit minitablets of Nimodipine without using a gas-generating agent: in vitro and in vivo characterization
}

\author{
M. Panda ${ }^{1 *}$, M. E. B. Rao ${ }^{1}$, C. N. Patra ${ }^{1}$, J. Panda ${ }^{1}$, K. C. Panigrahi ${ }^{1}$ and G. Patro ${ }^{2}$
}

\begin{abstract}
Background: Floating drug delivery systems have been reported for different active pharmaceutical ingredients as single-unit tablets with gas-generating agents. In this present research, the formulation of floating multiple-unit minitablets of Nimodipine without using gas-generating agent was attempted with an objective of increased residence time, sustain-release and improved oral bioavailability. Solid dispersion with different ratios (1:0.5, 1:1, 1: $1.5,1: 2,1: 2.5)$ of drug with the lipophilic carrier such as Compritol ATO 888, Gelucire 43/01, G39/01 and Precirol ATO 05 was formulated using melt granulation technique. The adsorbent Sylysia 350 to lipophilic carrier is maintained at 1:1. The granules were compressed into minitablets weighing $15 \mathrm{mg}$ and were filled into a ' 0 ' size capsule.

Results: Differential scanning calorimetry study justified no interaction of the drug with excipients. The formulations which exhibited desirable flow property, floating lag time less than $1 \mathrm{~min}$ and floating time of $12 \mathrm{~h}$ were further characterized for various post-compression parameters. The optimized single-dose (capsule) of floating multiple-unit minitablets of Nimodipine consisting of $60 \mathrm{mg}$ of drug, $120 \mathrm{mg}$ of G43/01 and $120 \mathrm{mg}$ of Sylysia 350 showed an average of floating lag time within $24.48 \mathrm{~s}$, floating time of $14.32 \mathrm{~h}$ and sustained-release up to $12 \mathrm{~h}$.

Pharmacokinetic study of the optimized formulation (F9) showed nearly 2.5 times increase in area under the curve with increased residence time in comparison to aqueous suspension of Nimodipine. The stability study revealed no significant change in various parameters before and after storage.
\end{abstract}

Conclusion: Hence, gelucire 43/01-based multiple-unit minitablets of Nimodipine can be considered a promising approach for sustaining the drug release with gastric retention for $12 \mathrm{~h}$ without using gas-generating agent.

Keywords: Floating multiple unit minitablets, Pharmacokinetic study, Lipophilic carriers

\section{Background}

For a long time, oral-controlled release (CR) formulations are popularly used for controlling the release of drugs. Short transit time of drug with the absorption window in the stomach causes the release of drug in the non-absorbing distal segment of GIT leading to poor bioavailability $[1,2]$. These features are responsible for the design of gastroretentive formulations [3, 4]. Dose-dumping is the main disadvantage associated with sustained-release single-unit

\footnotetext{
* Correspondence: madhupanda026@gmail.com

${ }^{1}$ Roland Institute of Pharmaceutical Sciences, Berhampur, Biju Patnaik

University of Technology, Rourkela, Odisha 760010, India

Full list of author information is available at the end of the article
}

dosage form due to polymer failure $[5,6]$. Like other multiple-unit systems, minitablets can be considered a promising approach which releases the drug from the subunits (minitablets) after the disintegration of capsule $[7,8]$.

The drug having short biological half-life favours development of a sustained-release (SR) while drug with absorption window in upper GI tract favours the development of floating drug delivery system, respectively [9-12]. Even though Nimodipine was developed as a calcium channel blocker, but later, it was used more frequently in preventing a major complication of subarachnoid haemorrhage. Hydrophobic polymer can be used in the preparation of sustained and floating formulations. Hydrophobicity of certain carriers 
such as Compritol ATO 888 (COM), Gelucire 43/01(G43/ 01), Gelucire 39/01 (G39/01) and precirol ATO 05 (PRE) is the reason for their release retarding ability [13]. Hydrophobic polymer retards the hydration rate of the matrix which results variability in release profile. Hydrophobicity of carriers such as COM, G43/01, G39/01 and PRE is due to the presence of the certain hydrophobic group in their molecular structure. It can be inferred from their low HLB value. This is the reason for retarding the matrix wetting rate by using these polymers as carrier. Their low melting point makes them suitable for melt granulation method thereby obviating the need for organic solvents for solubilization. The higher concentration of lipophilic carriers promotes better control of the drug release because of the increase of lipid matrix density and long diffusion path length $[14,15]$. Many researchers have attempted floating granules and tablets using lipid carriers alone and also in combination with polymers like hydroxypropylmethylcellulose and ethylcellulose [16]. Hence, in the present research work, it is planned to use hydrophobic carriers in the formulation of floating multiple-unit minitablets (FMM) of Nimodipine to achieve floating with sustain-release for $12 \mathrm{~h}$.

\section{Materials}

Nimodipine was received as a gift sample from Aurobindo Pharma (Hyderabad, India). SYL was kindly provided as ex-gratis by Fuji Chemicals Pvt. Ltd. (Japan). COM, G43/ 01, G39/01 and PRE were provided as gift samples from Gattefosse Pvt. Ltd. (Mumbai, India). All other chemicals and solvents were of analytical grade or highest quality and were used as such as obtained.

\section{Methods}

\section{Preparation of FMM of Nimodipine}

Melt granulation technique was adopted for preparing the solid dispersion of Nimodipine and lipophilic carrier such as COM, G43/01, G39/01 and PRE. The lipophilic carrier was heated on a water bath in a temperature range of 50 to $60^{\circ} \mathrm{C}$ with continuous stirring. To the molten lipid dispersion, Nimodipine powder was added and stirred for $10 \mathrm{~min}$. The SYL in 1:1 ratio with lipophilic carrier was added to the dispersion with continued mixing for $10 \mathrm{~min}$ in order to solidify the molten mass. Then, solid dispersion was sieved through mesh no. \# 40. The resultant granules were compressed into 3-mm circular minitablets and were filled into a gelatine capsule of size '0' [17].

\section{Compatibility studies using differential scanning calorimeter}

The pure drug Nimodipine and its solid dispersions with carriers were examined for compatibility study employing DSC (Shimazu Ltd., Japan). All the accurately weighed samples were placed in sealed aluminum pans before placing the pan on sample holder at a scanning rate of $10^{\circ} \mathrm{C} /$ min from room temperature up to $220^{\circ} \mathrm{C}$. An empty aluminum pan was used as a reference. The DSC curve was plotted over a temperature range in order to predict the thermodynamic compatibility [18].

\section{Micromeritic properties of granules}

The pure drug Nimodipine and solid dispersion granules of all the prepared formulations were characterised for various micromeritic properties. The bulk density, tap density, angle of repose, Carr's Index, and Hausner's ratio of all the formulations were determined as per standard procedure [19].

\section{In vitro buoyancy studies}

\section{Measurement of floating lag time}

The FLT was determined by conducting in vitro buoyancy studies for each of the formulation. The required number of FMM was placed in a beaker containing 100 $\mathrm{mL}$ of $0.1 \mathrm{~N} \mathrm{HCl}$. FLT may be defined as the time required for each of the minitablets to start floating on the surface of the dissolution media [20].

\section{Measurement of floating time}

FMM tablets were placed in USP dissolution apparatusII containing $900 \mathrm{~mL}$ of $0.1 \mathrm{~N} \mathrm{HCl}$ to determine FT of each formulation. FT is the total time or duration of floating when a dosage form is placed in a dissolution media [21].

\section{Evaluation of post-compression parameters}

The compressed minitablets were subjected to various quality control tests such as weight variation, hardness, friability, disintegration and drug content as per the standard procedure [22]. Weight variation was determined by weighing 20 minitablets individually, hardness was determined by taking 6 tablets from each formulation using a digital hardness tester (Electro lab Ltd., India), friability was determined taking minitablets equivalent to $6.5 \mathrm{~g}$ in a Roche $^{\circ}$ friabilator (Electrolab Pvt. Ltd., India), which was rotated for $4 \mathrm{~min}$ at $25 \mathrm{rpm}$. The disintegration test was performed for $1 \mathrm{~h}$ in $0.1 \mathrm{~N} \mathrm{HCl}$ by taking 6 minitablets. Drug content was determined by taking ten weighed minitablets from each formulation and finely powdered. The powder equivalent to $25 \mathrm{mg}$ of Nimodipine was weighed and taken in a $25-\mathrm{ml}$ volumetric flask, extracted with 0.1 $\mathrm{N} \mathrm{HCl}$. The mixture was then filtered and $1 \mathrm{ml}$ of the filtrate was suitably diluted and analysed at $350 \mathrm{~nm}$ spectrophotometrically.

\section{In vitro dissolution studies}

The in vitro dissolution studies of different FMM were conducted in a USP dissolution apparatus-II (paddle method with a paddle speed of $50 \mathrm{rpm}$ ) taking $900 \mathrm{~mL}$ $0.1 \mathrm{~N} \mathrm{HCl}$ as dissolution medium maintained at $37 \pm$ 
Table 1 Composition of nimodipine solid dispersion systems

\begin{tabular}{|c|c|c|c|c|c|c|}
\hline Formulations & Nimodipine (g) & Compritol ATO 888 (g) & Gelucire 43/01 (g) & Gelucire 39/01 (g) & Precirol ATO 5 (g) & Sylysia $350(\mathrm{~g})$ \\
\hline$\overline{F 1}$ & 1 & 0.5 & - & - & - & 0.5 \\
\hline $\mathrm{F} 2$ & 1 & 1 & - & - & - & 1 \\
\hline F3 & 1 & 1.5 & - & - & - & 1.5 \\
\hline F4 & 1 & 2 & - & - & - & 2 \\
\hline F5 & 1 & 2.5 & - & - & - & 2.5 \\
\hline F6 & 1 & - & 0.5 & - & - & 0.5 \\
\hline F7 & 1 & - & 1 & - & - & 1 \\
\hline F8 & 1 & - & 1.5 & - & - & 1.5 \\
\hline F9 & 1 & - & 2 & - & - & 2 \\
\hline F10 & 1 & - & 2.5 & - & - & 2.5 \\
\hline F11 & 1 & - & - & 0.5 & - & 0.5 \\
\hline $\mathrm{F} 12$ & 1 & - & - & 1 & - & 1 \\
\hline F13 & 1 & - & - & 1.5 & - & 1.5 \\
\hline F14 & 1 & - & - & 2 & - & 2 \\
\hline F15 & 1 & - & - & 2.5 & - & 2.5 \\
\hline F16 & 1 & - & - & - & 0.5 & 0.5 \\
\hline F17 & 1 & - & - & - & 1 & 1 \\
\hline F18 & 1 & - & - & - & 1.5 & 1.5 \\
\hline F19 & 1 & - & - & - & 2 & 2 \\
\hline F20 & 1 & - & - & - & 2.5 & 2.5 \\
\hline
\end{tabular}

Table 2 Composition of minitablet (weight of each minitablet $15 \mathrm{mg}$ )

\begin{tabular}{|c|c|c|c|c|c|c|c|}
\hline \multirow[t]{2}{*}{ Formulation } & \multicolumn{6}{|c|}{ Quantity drug and excipient $(\mathrm{mg})$ in each solid dispersion formulation } & \multirow{2}{*}{$\begin{array}{l}\text { Number } \\
\text { of } \\
\text { tablets } \\
\text { for } 60 \\
\text { mg dose }\end{array}$} \\
\hline & Nimodipine & Compritol ATO 888 & Gelucire 43/01 & Gelucire 39/01 & Precirol ATO 5 & Sylysia 350 & \\
\hline$\overline{\mathrm{F} 1}$ & 7.5 & 3.75 & - & - & - & 3.75 & 8 \\
\hline $\mathrm{F} 2$ & 5 & 5 & - & - & - & 5 & 12 \\
\hline F3 & 3.75 & 5.625 & - & - & - & 5.625 & 16 \\
\hline F4 & 3 & 6 & - & - & - & 6 & 20 \\
\hline F5 & 2.5 & 6.25 & - & - & - & 6.25 & 24 \\
\hline F6 & 7.5 & - & 3.75 & - & - & 3.75 & 8 \\
\hline F7 & 5 & - & 5 & - & - & 5 & 12 \\
\hline F8 & 3.75 & - & 5.625 & - & - & 5.625 & 16 \\
\hline F9 & 3 & - & 6 & - & - & 6 & 20 \\
\hline F10 & 2.5 & - & 6.25 & - & - & 6.25 & 24 \\
\hline F11 & 7.5 & - & - & 3.75 & - & 3.75 & 8 \\
\hline $\mathrm{F} 12$ & 5 & - & - & 5 & - & 5 & 12 \\
\hline F13 & 3.75 & - & - & 5.625 & - & 5.625 & 16 \\
\hline F14 & 3 & - & - & 6 & - & 6 & 20 \\
\hline F15 & 2.5 & - & - & 6.25 & - & 6.25 & 24 \\
\hline F16 & 7.5 & - & - & - & 3.75 & 3.75 & 8 \\
\hline F17 & 5 & - & - & - & 5 & 5 & 12 \\
\hline F18 & 3.75 & - & - & - & 5.625 & 5.625 & 16 \\
\hline F19 & 3 & - & - & - & 6 & 6 & 20 \\
\hline F20 & 2.5 & - & - & - & 6.25 & 6.25 & 24 \\
\hline
\end{tabular}


$0.5^{\circ} \mathrm{C}$. A total of $5 \mathrm{~mL}$ sample was withdrawn at regular time intervals up to $12 \mathrm{~h}(0.5,1,1.5,2,4,6,8,10$ and 12 h) and were analysed using UV-spectrophotometer at $354 \mathrm{~nm}$. The kinetics of drug release were analysed from the dissolution data by using zero-order, first order, Higuchi, and Korsmeyer-Peppas model [23, 24].

Zero order equation is $Q=K_{0} t$.

First order equation is $\ln (100-Q)=\ln 100-K_{1} t$

Higuchi Equation is $Q=K_{2} \sqrt{ } t$

Korsmeyer Peppa's equation is $\log \frac{M_{t}}{M_{\infty}}=\log K+n \log t$

where $\mathrm{Q}$ is the amount of drug released at time $\mathrm{t}, K_{0}$ zero order release rate constant, $K_{1}$ is first order release rate constant, the time, $K_{2}$ diffusion rate constant, is the amount of drug released at time t, $M_{t}$ is the amount of drug released at time $t, M_{\infty}$ is the amount of drug released at infinite time, initial amount of the drug in solution, $K$ release rate constant and $n$ is diffusional exponent.

\section{Stability study}

Stability study of the prepared FMM of Nimodipine was conducted for a period of 6 months as prescribed in $\mathrm{ICH}$ guidelines. The formulations were examined at the time points of $0,1,3$ and 6 months for the different parameters [25].

\section{In vivo pharmacokinetic study}

Twelve number of male albino rabbits of body weight $1.5 \mathrm{~kg}$ were selected from the stock of animal house. They were divided into 2 groups having 6 animals in each group for test (minitablet administration) and standard (aqueous suspension of nimodipine). They were treated with hygienic food and fresh water twice daily. All animals were maintained for a wash-out period of 15 days prior to the study. The dose of nimodipine was calculated as 4.2 $\mathrm{mg}$ for each rabbit of weight approx. $1.5 \mathrm{~kg}$.

\section{The dose for rabbit was calculated as follows}

$$
\begin{aligned}
& \text { Total dose }(\text { in humans }) \times 0.07 \text { (factor for each } 1.5 \mathrm{~kg} \text { weight of rabbit }) \\
& \quad=(60 \times 0.07 \times 1.5) / 1.5=4.2 \mathrm{mg} \text { for } 1.5 \mathrm{~kg} \text { rabbit }
\end{aligned}
$$

The optimised formulation (minitablet) and aqueous dispersion of Nimodipine were administered in the form of dispersion to six male rabbits each in two groups using Ryle's tube [26]. At different time points $(0.5,2,4,8,12$ and $24 \mathrm{~h})$, blood sample of $0.5 \mathrm{~mL}$ was withdrawn from the marginal ear vein of the rabbit. Each blood samples was centrifuged for $10 \mathrm{~min}$ at 3000 rpm and the supernatant layer, i.e. serum was collected using micropipette. All the samples were analysed using

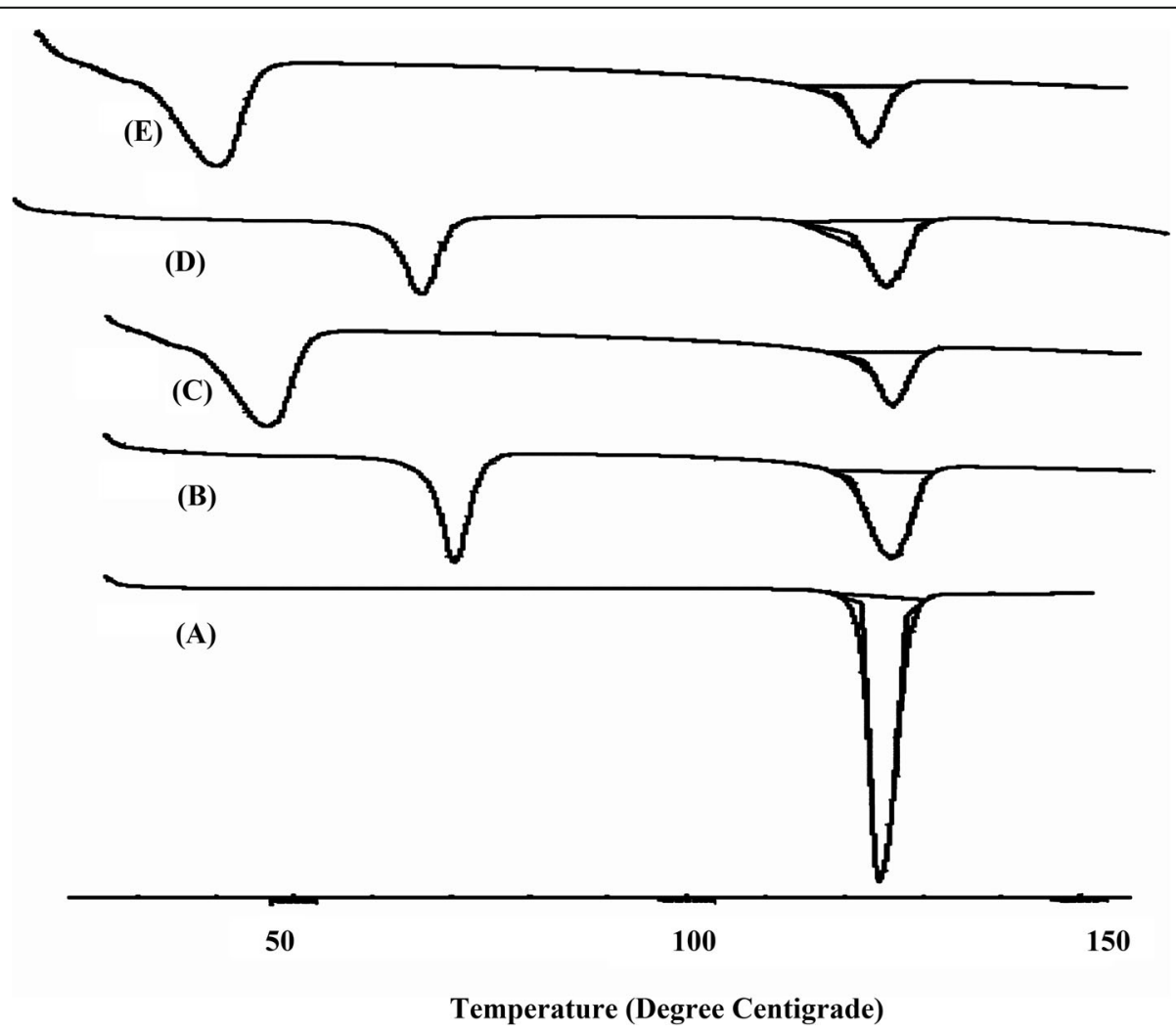

Fig. 1 DSC thermo-gram of a: pure drug Nimodipine, b: solid dispersion of Nimodipine with Compritol ATO 888 (1:1), c: Solid dispersion of Nimodipine with Gelucire 43/01 (1:1), d: Solid dispersion of Nimodipine with Gelucire 39/01(1:1), e: Solid dispersion of Nimodipine with Precirol ATO 05(1:1) 
reverse-phase ultrafast liquid chromatographic (UFLC) method. The various pharmacokinetic parameters like elimination rate constant $(K)$, half-life $\left(t_{1 / 2}\right)$, peak plasma concentration (Cmax), time to attain the peak plasma concentration (Tmax), area under the curve (AUC) and area under the first moment curve (AUMC) were calculated. The animal experiments complied with the ARRIVE guidelines and carried out in accordance with the U.K. Animals (Scientific Procedures) Act, 1986 and associated guidelines, EU Directive 2010/63/EU for animal experiments. The pharmacokinetic study was approved by Institutional Animals Ethics committee [926/PO/Re/5/06/CPCSEA, Approval No.97]. Anaesthetic agents are not used since the procedures associated with routine blood withdrawal. Euthanasia method is not applicable for this study since the animals were rehabilitated after the study period as per the standard procedure. The animals were procured from Saha Enterprise, Kolkata, India (CPCSEA Regd no: 1828/PO/ Bt/S/15/CPCSEA).

\section{Results}

The composition of solid dispersion with different ratios (1:0.5, 1:1, 1:1.5, 1:2, 1:2.5) of drug with the lipophilic

Table 3 Micromertics properties of solid dispersions

\begin{tabular}{|c|c|c|c|}
\hline Formulations & $\begin{array}{l}\text { *Angle of repose } \\
\left({ }^{0}\right)\end{array}$ & $\begin{array}{l}{ }^{*} \text { Carr's index } \\
\text { (C.I) }\end{array}$ & $\begin{array}{l}\text { *Hausner's ratio } \\
\text { (H.R) }\end{array}$ \\
\hline Nimodipine & $42 \pm 2.4$ & $29 \pm 2.1$ & $1.46 \pm 0.8$ \\
\hline F1 & $24.23 \pm 2.1$ & $15.62 \pm 1.6$ & $1.19 \pm 0.4$ \\
\hline F2 & $22.67 \pm 1.9$ & $16.18 \pm 1.2$ & $1.22 \pm 0.7$ \\
\hline F3 & $22.48 \pm 2.2$ & $14.42 \pm 1.2$ & $1.18 \pm 0.2$ \\
\hline $\mathrm{F} 4$ & $20.67 \pm 1.9$ & $16.89 \pm 1.2$ & $1.22 \pm 0.7$ \\
\hline F5 & $24.23 \pm 2.1$ & $17.62 \pm 1.6$ & $1.19 \pm 0.4$ \\
\hline F6 & $23.23 \pm 2.1$ & $15.62 \pm 1.6$ & $1.19 \pm 0.4$ \\
\hline F7 & $22.67 \pm 1.9$ & $16.89 \pm 1.2$ & $1.22 \pm 0.7$ \\
\hline F8 & $22.48 \pm 2.2$ & $15.39 \pm 1.2$ & $1.18 \pm 0.2$ \\
\hline F9 & $24.48 \pm 2.2$ & $14.32 \pm 1.2$ & $1.18 \pm 0.2$ \\
\hline F10 & $21.67 \pm 1.9$ & $18.89 \pm 1.2$ & $1.22 \pm 0.7$ \\
\hline F11 & $22.23 \pm 2.1$ & $16.62 \pm 1.6$ & $1.19 \pm 0.4$ \\
\hline $\mathrm{F} 12$ & $24.67 \pm 1.9$ & $17.89 \pm 1.2$ & $1.22 \pm 0.7$ \\
\hline F13 & $22.48 \pm 2.2$ & $15.46 \pm 1.2$ & $1.19 \pm 0.2$ \\
\hline F14 & $24.48 \pm 2.2$ & $14.25 \pm 1.2$ & $1.18 \pm 0.2$ \\
\hline F15 & $22.67 \pm 1.9$ & $16.89 \pm 1.2$ & $1.22 \pm 0.7$ \\
\hline F16 & $21.54 \pm 2.1$ & $17.13 \pm 1.6$ & $1.15 \pm 0.4$ \\
\hline F17 & $23.61 \pm 1.9$ & $16.16 \pm 1.4$ & $1.23 \pm 0.3$ \\
\hline F18 & $21.24 \pm 3.1$ & $14.31 \pm 1.2$ & $1.22 \pm 0.2$ \\
\hline F19 & $25.15 \pm 2.2$ & $15.16 \pm 2.6$ & $1.21 \pm 0.2$ \\
\hline F20 & $21.56 \pm 1.9$ & $13.14 \pm 1.2$ & $1.19 \pm 0.7$ \\
\hline
\end{tabular}

*Mean $\pm \mathrm{SD}, n=6$ carrier such as COM, G43/01, G39/01 and PRE are given in Table 1 . The adsorbent SYL to lipophilic carrier is maintained at 1:1. Each minitablet weighing $15 \mathrm{mg}$ is filled into a ' 0 ' size capsule. The composition of each formulation of FMM is illustrated in Table 2.

\section{Compatibility studies using differential scanning calorimeter}

FMM DSC study revealed that the pure drug Nimodipine showed a sharp endothermic peak at $124.6{ }^{\circ} \mathrm{C}$ with a narrow melting range with an onset temperature of $122{ }^{\circ} \mathrm{C}$ and end set temperature of $128^{\circ} \mathrm{C}$. The peaks remained nearly the same in all representative formulation such as F1, F6, F11 and F16. Figure 1 confirms that no significant overlapping or shifting of the peak in the thermograms, however, broadening of peaks was observed in all formulations indicating the formation of solid dispersion.

\section{Micromeritic properties of granules}

The micromeritic parameters for all the formulation as well as the pure drug were studied and the results are depicted in Table 3. The micromeritic properties of pure drug revealed that the flowability and compressibility were very poor for processing into tablet dosage form. All the

Table 4 Determination of density, floating lag time and floating time of minitablets

\begin{tabular}{lllll}
\hline Formulations & $\begin{array}{l}{ }^{*} \text { Density } \\
\left(\mathrm{g} \cdot \mathrm{cm}^{-3}\right)\end{array}$ & $\begin{array}{l}{ }^{*} \text { Floating lag } \\
\text { time }(\mathrm{s})\end{array}$ & $\begin{array}{l}\text { *Floating } \\
\text { duration }(\mathrm{h})\end{array}$ & $\begin{array}{l}{ }^{*} \% \\
\text { Floating }\end{array}$ \\
\hline F1 & $0.20 \pm 0.01$ & $\mathrm{NF}$ & $\mathrm{IF}$ & $\mathrm{IF}$ \\
F2 & $0.21 \pm 0.02$ & $\mathrm{NF}$ & $\mathrm{IF}$ & $\mathrm{IF}$ \\
F3 & $0.24 \pm 0.01$ & $235 \pm 12$ & $1 \pm 0.06$ & $50 \pm 2$ \\
F4 & $0.22 \pm 0.01$ & $128 \pm 7$ & $1.5 \pm 0.08$ & $70 \pm 3$ \\
F5 & $0.21 \pm 0.03$ & $85 \pm 3$ & $1 \pm 0.04$ & $80 \pm 2$ \\
F6 & $0.21 \pm 0.01$ & $65 \pm 2$ & $6 \pm 0.2$ & $90 \pm 4$ \\
F7 & $0.20 \pm 0.02$ & $56 \pm 2$ & $10 \pm 0.3$ & $95 \pm 2$ \\
F8 & $0.21 \pm 0.02$ & $35 \pm 3$ & $12 \pm 0.4$ & $94 \pm 3$ \\
F9 & $0.24 \pm 0.02$ & $18 \pm 1$ & $14 \pm 0.3$ & $100 \pm 4$ \\
F10 & $0.23 \pm 0.01$ & $15 \pm 1$ & $16 \pm 0.2$ & $100 \pm 3$ \\
F11 & $0.20 \pm 0.01$ & $70 \pm 2$ & $7 \pm 0.2$ & $92 \pm 3$ \\
F12 & $0.24 \pm 0.02$ & $62 \pm 3$ & $9 \pm 0.3$ & $96 \pm 4$ \\
F13 & $0.20 \pm 0.01$ & $38 \pm 2$ & $11 \pm 0.2$ & $94 \pm 3$ \\
F14 & $0.23 \pm 0.01$ & $22 \pm 1$ & $14 \pm 0.4$ & $98 \pm 3$ \\
F15 & $0.21 \pm 0.03$ & $17 \pm 1$ & $16 \pm 0.3$ & $100 \pm 3$ \\
F16 & $0.22 \pm 0.01$ & NF & IF & F \\
F17 & $0.24 \pm 0.01$ & NF & FF & F \\
F18 & $0.21 \pm 0.02$ & $345 \pm 11$ & $1.5 \pm 0.06$ & $45 \pm 2$ \\
F19 & $0.23 \pm 0.02$ & $226 \pm 8$ & $1.2 \pm 0.04$ & $65 \pm 3$ \\
F20 & $0.23 \pm 0.01$ & $175 \pm 9$ & $2 \pm 0.01$ & $70 \pm 2$ \\
\hline F & &
\end{tabular}

*Mean $\pm S D, n=6, N F$ Not Floating, IF Instant floating 
Table 5 Quality control tests of minitablets

\begin{tabular}{|c|c|c|c|c|}
\hline Formulations & *Drug content (\%) & ${ }^{*}$ Hardness (Kg/sq. cm) & ${ }^{*}$ Friability (\%) & Disintegration test for $1 \mathrm{~h}$ \\
\hline F8 & $98.5 \pm 2.1$ & $4.1 \pm 0.3$ & $0.1 \pm 0.004$ & Not disintegrated \\
\hline F9 & $98 \pm 3.4$ & $4.5 \pm 0.4$ & $0.8 \pm 0.03$ & Not disintegrated \\
\hline F10 & $98.5 \pm 3.2$ & $5.2 \pm 0.2$ & $0.7 \pm 0.02$ & Not disintegrated \\
\hline F14 & $98 \pm 4.3$ & $4.9 \pm 0.2$ & $0.6 \pm 0.02$ & Not disintegrated \\
\hline F15 & $99 \pm 4.2$ & $5.6 \pm 0.3$ & $0.4 \pm 0.01$ & Not disintegrated \\
\hline
\end{tabular}

${ }^{*}$ Mean \pm SD, $n=6$

dispersion granules showed that the value of angle of repose, C. I and H. R were within the specified limit.

\section{In vitro buoyancy studies}

The in vitro buoyancy study was done and the value of density, floating lag time and floating time for all the prepared formulations are illustrated in Table 4. As the density of all FMM was much lower than the density of GI fluid, it was expected that all minitablets will float. However, peculiar results were observed in floating behaviour. Minitablets formulated with G43/01 and G39/ 01 showed an excellent floating behaviour with less than 1 min floating lag time and floating duration of more than $12 \mathrm{~h}$ (F8, F9, F10, F14 and F15) whereas FMM formulated with COM and PRE did not exhibit floating in spite of low density of minitablets [27].

\section{Evaluation of post-compression parameters}

The result of the quality control test of the different formulations F8, F9, F10, F14 and F15 is depicted in Table 5. The obtained result showed that the various parameters such as drug content, hardness, friability, disintegration test were within the acceptable specification.

\section{In vitro dissolution studies}

The in vitro dissolution study of the formulations was carried out and the plot of cumulative percentage drug release against time is illustrated in Fig. 2. The resultant plot suggests that formulation F9 and F14 found to achieve the desirability of sustaining the drug release for $12 \mathrm{~h}$. The results of different drug release kinetic coefficients for formulation F8, F9, F10, F14 and F15 infer higher correlation coefficient for zero-order release kinetics. All formulations

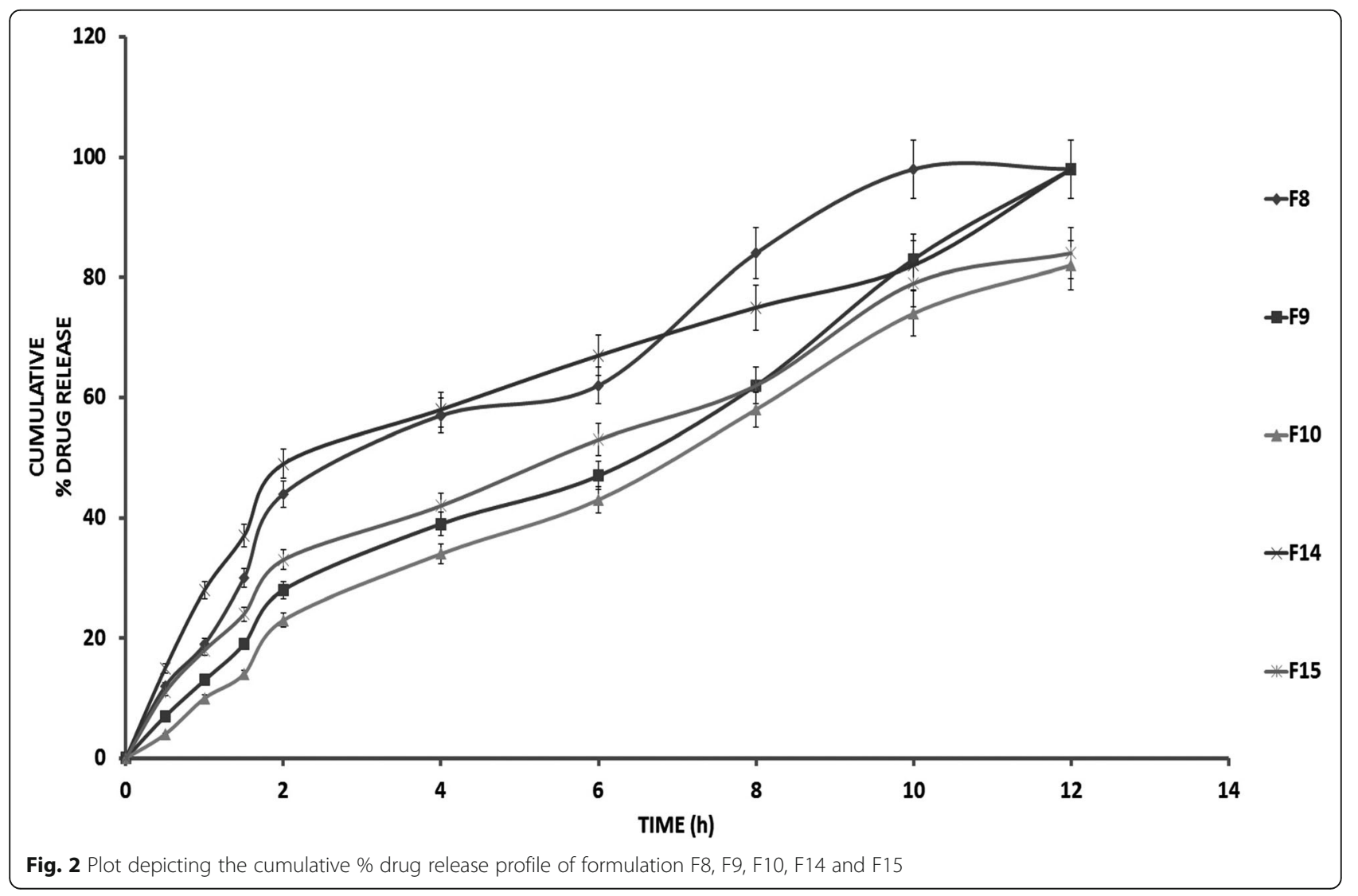


Table 6 Accelerated stability study

\begin{tabular}{|c|c|c|c|c|c|c|c|c|}
\hline \multirow{2}{*}{$\begin{array}{l}\text { Time in } \\
\text { months }\end{array}$} & \multicolumn{4}{|c|}{ Characterisation of F9 formulation } & \multicolumn{4}{|c|}{ Characterisation of F14 formulation } \\
\hline & $\begin{array}{l}\text { Drug content } \\
(\%)^{*}\end{array}$ & $\begin{array}{l}\text { Floating lag time } \\
(\mathrm{s})^{*}\end{array}$ & $\begin{array}{l}\text { Floating duration } \\
\text { (h)* }\end{array}$ & T95\%* & $\begin{array}{l}\text { Drug content } \\
(\%)^{*}\end{array}$ & $\begin{array}{l}\text { Floating lag time } \\
\text { (h)* }\end{array}$ & $\begin{array}{l}\text { Floating duration } \\
(\text { h)* }\end{array}$ & T95\% (h)* \\
\hline 0 & $98 \pm 3.4$ & $18 \pm 1$ & $14 \pm 0.3$ & $12 \pm 0.4$ & $98 \pm 4.3$ & $22 \pm 1$ & $14 \pm 0.4$ & $12 \pm 0.6$ \\
\hline 1 & $97.5 \pm 2.1$ & $16 \pm 0.5$ & $13.5 \pm 0.5$ & $12 \pm 0.2$ & $97 \pm 3.2$ & $20 \pm 0.7$ & $11.5 \pm 0.3$ & $10.5 \pm 0.5$ \\
\hline 3 & $97 \pm 2.6$ & $14 \pm 0.6$ & $13 \pm 0.2$ & $12 \pm 0.1$ & $96.5 \pm 2.5$ & $18 \pm 0.5$ & $10.5 \pm 0.7$ & $10 \pm 0.3$ \\
\hline 6 & $97 \pm 3.1$ & $15 \pm 1$ & $13 \pm 0.4$ & $12 \pm 0.2$ & $96 \pm 4.1$ & $13 \pm 0.6$ & $9 \pm 0.3$ & $9.5 \pm 0.4$ \\
\hline
\end{tabular}

*Mean \pm SD, $n=6$, T95\%: Time required for more than 95\% drug release

exhibited a higher correlation for Higuchi equation. All formulations showed release exponent greater than 0.5 less than 1.

\section{Accelerated stability study}

Formulation F9 and F14 were examined for 6 months of stability study as prescribed in the method section. The parameters such as drug content, FLT, FT, time for more than 95 percentage drug release (T95\%) of F9 and F14 at various intervals are illustrated in Table 6. These values indicated that there is no significant change in the parameters during the stability study period for F9. However, it was found that parameters such as FLT, FT and T95\% significantly changed for F14 formulation. Hence, FMM formulation F9 was selected for further pharmacokinetic study.

\section{In vivo pharmacokinetic study}

Figure 3 illustrates the mean serum drug concentration of nimodipine vs. time graph of the optimized formulation F9 and pure drug after conducting the pharmacokinetic study. UFLC method for estimation of Nimodipine using mobile phase acetonitrile: water (70:30), C18 column, flow rate $1 \mathrm{ml} / \mathrm{min}$ estimates retention time of $5.39 \mathrm{~min}$. Table 7 illustrates the calculated values of different pharmacokinetic parameters. The Tmax for the pure drug was found to be $4 \mathrm{~h}$ whereas Tmax in case of best formulation (F9) formulation was found to be $5 \mathrm{~h}$, indicating slow release of the drug. The AUC value of F9 was 57,438.19 ng.h/ml, whereas it was found to be $21,678.98 \mathrm{ng} . \mathrm{h} / \mathrm{ml}$ for pure drug indicating that SR FMM (F9) showed better bioavailability, which is nearly 2.5 times than that of the pure drug nimodipine. Cmax for Nimodipine was found to be $2882.95 \mathrm{ng} / \mathrm{mL}$ whereas for optimized formulation, it was found to be $3498.21 \mathrm{ng} / \mathrm{ml}$. Nearly 1.2 times increase in Cmax value for F9 indicated better absorption of the drug from the formulation. Elimination rate constant for pure drug and F9 was 288.12 and 382.94 respectively. Higher mean residence time (MRT) for F9 indicates increased residence time of the dosage form.

\section{Discussion}

Each of the prepared minitablet consists of a particular composition of lipophilic carrier (such as COM, G43/01,

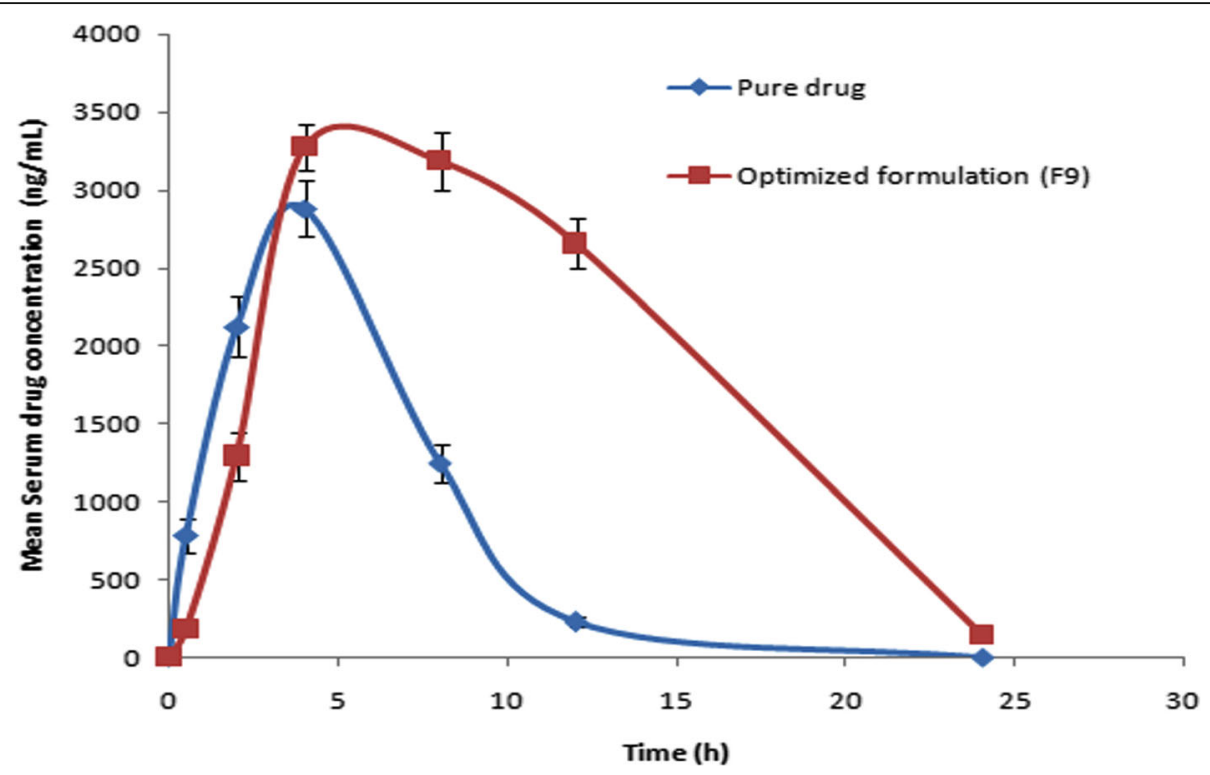

Fig. 3 Plot depicting the mean serum concentration vs time of optimized FMM and Pure drug Nimodipine 
Table 7 Determination of in vivo pharmacokinetic parameters

\begin{tabular}{lll}
\hline Pharmacokinetic parameters & Nimodipine & OPT. formulation \\
\hline${ }^{*} \mathrm{~K}\left(\mathrm{~h}^{-1}\right)$ & $0.308 \pm 0.012$ & $0.054 \pm 0.002$ \\
${ }^{*} \mathrm{C}_{\max }(\mathrm{ng} / \mathrm{mL})$ & $2882.95 \pm 123$ & $3498.21 \pm 152$ \\
${ }^{*} \mathrm{~T}_{\max }(\mathrm{h})$ & $4 \pm 0.1$ & $5 \pm 0.2$ \\
${ }^{*} \mathrm{AUC}(\mathrm{ng} . \mathrm{h} / \mathrm{mL})$ & $21,678.98 \pm 78$ & $57,438.19 \pm 54$ \\
${ }^{*} \mathrm{AUMC}\left(\mathrm{ng} \cdot \mathrm{h}^{2} / \mathrm{mL}\right)$ & $66,337.67 \pm 98$ & $445,145.97 \pm 58$ \\
${ }^{*}$ MRT $(\mathrm{h})$ & $3.06 \pm 0.12$ & $7.75 \pm 0.32$ \\
\hline
\end{tabular}

${ }^{*}$ Mean $\pm S D, n=6$

G39/01 and PRE), adsorbent SYL and drug. These results of DSC ratifies that the carriers used in the present study are compatible with nimodipine. This may be due to the engulfment of the drug in the molecular structure of the lipid matrix. Due to high oil adsorption capacity, high specific surface area of SYL, it helps to improve compressibility and flowability of the prepared dispersion which can be predicted from their micromeritic properties.

Minitablets formulated with G43/01 and G39/01(F8, F9, F10, F14 and F15) showed excellent floating behaviour with desired floating lag time and floating time. Whereas FMM formulated with COM and PRE do not achieve the desirability. The in vitro buoyancy study reveals that hydrophobic lipid coat around the surface of drug particle is the prime reason for floating behaviour. It is also predicted that hydrophobicity and density alone may not responsible for achieving desirable floating. Nature of the lipid matrix also played a significant role in achieving desired floating characteristics.

F9 and F14 found to achieve the desirability of sustaining the drug release for $12 \mathrm{~h}$. Hence, lipid carrier G43/01 and G39/01 are effective in controlling the drug release in a particular composition. The higher correlation coefficient for Higuchi equation suggests drug release was primarily by diffusion mechanism. All formulations showed release exponent greater than 0.5 and less than 1 , signifying non-fickian diffusion-controlled release mechanism. Hence, on the basis of dissolution study, F9 and F14 can be predicted to satisfy all the criteria for a floating multiple unit minitablet.

Formulation F9 and F14 were examined for 6 months of stability study which revealed no significant change of the parameters during the stability study period for F9. However, it was found that parameters such as FLT, FT and T95\% significantly changed for F14 formulation which may be attributed to softening of G39/01 based FMM at the stability study temperature of $40^{\circ}$ due to its low melting point.

Pharmacokinetic study showed higher Cmax for minitablets because of the increased residence time of floating minitablets in the upper part of the GI tract, i.e. the absorption window for Nimodipine. Longer Tmax for the optimized minitablet (F9) can be attributed to slow release of drug from the hydrophobic matrix of G43/01. SR FMM (F9) showed better bioavailability, which is evident from 2.5 times increase in AUC. The better bioavailability is due to high residence time of the optimized formulation than that of the pure drug. Hence it may be inferred that it is possible to prepare gastro-retentive minitablets using G43/01 and G39/01 as lipid matrix without using gas-generating agent.

\section{Conclusion}

In this present research work, formulation and development of FMM Nimodipine were carried out with desired sustainability and gastric residence time. Solid dispersion with different ratios (1:0.5, 1:1, 1:1.5, 1:2, 1:2.5) of drug with the lipophilic carrier such as COM, G43/01, G39/01 and PRE was formulated using melt granulation technique. From the above research work, it may be concluded that sustain-release gastro-retentive minitablets can be prepared using both G43/01 and G39/01 without using gas generating agents. Whereas the same was not observed with PRE and COM-based minitablets inspite of similar hydrophobicity and density. Hence G43/01 based minitablets can be considered as the promising approach for formulation of sustain release with gastric retention. The pharmacokinetic profile of the optimized sustain release gastro-retentive minitablet was found to be superior as compared with aqueous suspension of pure drug, which can be therapeutically and commercially exploited.

\section{Abbreviations}

COM: Compritol ATO 888; DSC: Differential scanning calorimeter; FLT: Floating lag time; FMM: Floating multiple unit minitablets; FT: Floating time; G39/01: Gelucire 39/01; G43/01: Gelucire 43/01; Gl: Gastrointestinal; h: Hour; HCl: Hydrochloric acid; min: Minute; ng: Nanogram; OPT: Optimised; PRE: Precirol ATO 05; SR: Sustained-release; SYL: Sylysia 350; UV: Ultraviolet

\section{Acknowledgements}

Authors would like to thank the Principal and Management of Roland Institute of Pharmaceutical Sciences, Berhampur, India for providing necessary facilities to carry out the research work.

\section{Authors' contributions}

All authors (PM, RB, PN, PJ, PC and PG) have contributed to this research work. All authors have read and approved the manuscript. PM as

corresponding author executed the work and approved the manuscript from all co-authors. RB contributed to the conception and design of work. PN has substantially revised the manuscript. PJ has contributed in the interpretation of data. PK has assisted in the execution of research work. PG contributed in design of pharmacokinetic study.

\section{Funding}

No funding was received.

Availability of data and materials

All data and material are available upon request

\section{Ethics approval and consent to participate}

The animal experiments complied with the ARRIVE guidelines and carried out in accordance with the U.K. Animals (Scientific Procedures) Act, 1986 and associated guidelines, EU Directive 2010/63/EU for animal experiments. The pharmacokinetic study was approved by Institutional Animals Ethics committee [926/PO/Re/5/06/CPCSEA, Approval No.97]. 


\section{Consent for publication}

Not Applicable

\section{Competing interests}

The authors declare that they have no competing interests.

\section{Author details}

${ }^{1}$ Roland Institute of Pharmaceutical Sciences, Berhampur, Biju Patnaik University of Technology, Rourkela, Odisha 760010, India. ${ }^{2}$ College of Pharmaceutical Sciences, Berhampur, Odisha, India.

Received: 30 August 2019 Accepted: 30 January 2020

Published online: 11 February 2020

\section{References}

1. Thapa P, Jeong S (2018) Effects of formulation and process variables on gastroretentive floating tablets with a high-dose soluble drug and experimental design approach. Pharmaceutics 10(3):E161

2. Hoffman A (1998) Pharmacodynamic aspects of sustained release preparations. Adv Drug Deliv Rev 33(3):185-199

3. Streubel A, Siepmann J, Bodmeier R (2006) Gastroretentive drug delivery systems. Expert Opin Drug Deliv 3(2):217-233

4. Pawar VK, Kansal S, Garg G, Awasthi R, Singodia D, Kulkarni GT (2011) Gastroretentive dosage forms: a review with special emphasis on floating drug delivery systems. Drug Deliv 18(2):97-110

5. Abdul S, Chandewar AV, Jaiswal SB (2010) A flexible technology for modified-release drugs: multiple-unit pellet system (MUPS). J Control Release 147(1):2-16

6. Kawashima Y, Niwa T, Takeuchi H, Hino T, Ito Y (1991) Preparation of multiple unit hollow microspheres (microballoons) with acrylic resin containing tranilast and their drug release characteristics (in vitro) and floating behavior (in vivo). J Control Release 16(3):279-289

7. Lingam M, Ashok T, Venkateswarlu V, MadhusudanRao Y (2008) Design and evaluation of a novel matrix type multiple units as biphasic gastroretentive drug delivery systems. AAPS PharmSciTech 9(4):1253

8. Ichikawa M, Watanabe S, Miyake Y (1991) A new multiple-unit oral floating dosage system. I: preparation and in vitro evaluation of floating and sustained-release characteristics. J Pharm Sci 80(11):1062-1066

9. Singh BN, Kim KH (2000) Floating drug delivery systems: an approach to oral controlled drug delivery via gastric retention. J Control Release 63(3): 235-259

10. Lopes CM, Bettencourt C, Rossi A, Buttini F, Barata P (2016) Overview on gastroretentive drug delivery systems for improving drug bioavailability. Int J Pharma 510(1):144-158

11. Tomassoni D, Lanari A, Silvestrelli G, Traini E, Amenta F (2008) Nimodipine and its use in cerebrovascular disease: evidence from recent preclinical and controlled clinical studies. ClinExpHypertens 30(8):744-766

12. Wu W, Zhou Q, Zhang HB, Ma GD, Fu CD (1997) Studies on nimodipine sustained-release tablet capable of floating on gastric fluid with prolonged gastric resident time. Yao Xue Xue Bao 32(10):786-790

13. Panigrahi KC, Patra CN, Jena GK, Ghose D, Jena J, Panda SK (2018) Gelucire: a versatile polymer for modified release drug delivery system. Futur J Pharm Sci 4(1):102-108

14. Jain SK, Gupta A (2009) Development of gelucire 43/01 beads of metformin hydrochloride for floating delivery. AAPS PharmSciTech 10(4):1128

15. Patel DM, Patel NM, Patel VF, Bhatt DA (2007) Floating granules of ranitidine hydrochloride-gelucire 43/01: formulation optimization using factorial design. AAPS PharmSciTech 8(2):E25-E31

16. Mohamed MAE, Teaima MH, El-Monem RAA, Nabarawy NAE, Gaber DA (2017) Formulation, release characteristics, and bioavailability study of gastroretentive floating matrix tablet and floating raft system of Mebeverine HCl. Drug Des Devel Ther 11:1081-1093

17. Jammula S, Patra CN, Swain S, Panigrahi KC, Nayak S, Dinda SC (2015) Design and characterization of cefuroxime axetil biphasic floating minitablets. Drug Deliv 22(1):125-135

18. Zheng $X$, Yang $R$, Tang $X$, Zheng $L$ (2007) Part I: characterization of solid dispersions of nimodipine prepared by hot-melt extrusion. Drug Dev Ind Pharm 33(7):791-802

19. Fonner DE, Banker GS, Swarbrick J (1966) Micromeritics of granular pharmaceutical solids I: physical properties of particles prepared by five different granulation methods. J Pharm Sci 55(2):181-186
20. Arora S, Ali J, Ahuja A, Khar RK, Baboota S (2005) Floating drug delivery systems: a review. AAPS Pharm Sci Tech 6(3):E372-E390

21. Shakya R, Thapa P, Saha RN (2013) In vitro and in vivo evaluation of gastroretentive floating drug delivery system of ofloxacin. Asian J Pharm Sci 8(3):191-198

22. Aulton ME, Taylor K (2013) Aulton's pharmaceutics : the design and manufacture of medicines. Elsevier Health Science, London

23. Boldhane S, Kuchekar B (2010) Development and optimization of metoprolol succinate gastroretentive drug delivery system. Acta Pharma 60(4):415-425

24. Thakkar VT, Shah PA, Soni TG, Parmar MY, Gohel MC, Gandhi TR (2009) Goodness-of-fit model-dependent approach for release kinetics of levofloxacin hemihydrates floating tablet. DissolutionTechnol 16(1):35-39

25. Quality Guidelines: http://www.ich.org/products/guidelines/quality/article/ quality-quidelines.html. Accessed 20 Jan 2019

26. Panigrahi KC, Jena J, Jena GK, Patra CN, Rao MEB (2018) QBD-based systematic development of Bosentan SNEDDS: formulation, characterization and pharmacokinetic assessment. J Drug Deliv Sci Technol 47(October):31-42

27. Chauhan B, Shimpi S, Mahadik KR, Paradkar A (2005) Preparation and evaluation of floating risedronate sodium-gelucire1 43/01 formulations. Drug Dev Ind Pharm 31(9):851-860

\section{Publisher's Note}

Springer Nature remains neutral with regard to jurisdictional claims in published maps and institutional affiliations.

\section{Submit your manuscript to a SpringerOpen ${ }^{\circ}$ journal and benefit from:}

- Convenient online submission

- Rigorous peer review

- Open access: articles freely available online

- High visibility within the field

- Retaining the copyright to your article

Submit your next manuscript at $>$ springeropen.com 